\title{
Predictors of vocational interest
}

\author{
Vijay Pal Tewari ${ }^{1, *}$, H.M. Shailaja² \\ ${ }^{1}$ Guest Lecturer, ${ }^{2}$ Dean and Director (Retd.), Faculty of Education, Uday Degree College, Ayodhya, Uttar Pradesh, ${ }^{2}$ School of Education, \\ Rani Chanamma University, Belgaum, Karnataka, India \\ *Corresponding Author: Vijay Pal Tewari \\ Email: vijaypalt8@gmail.com
}

\begin{abstract}
Vocational interest has been identified as one of the impotent factors to assess the occupational choices, job stability and performance in the selected career besides being an unavoidable psychological trait in career counseling. It is noticed that numerous studies have been undertaken on vocational interest as an independent variable but despite being so important factor in the world of work, it has been explored nominal as to what extent cognitive and non-cognitive factors contribute in the development of interest in one Vocation more than the other. The present study aims to investigate the contribution of some of the important psychological traits in the prediction and development of vocational interests. 272 students of $\mathrm{X}^{\text {th }}$ standard from randomly selected 8 schools managed under defense sectors in three states of Karnataka, Tamil Nadu and A.P. were taken for the study. Data were collected using standardized tools. Multiple correlation and Regressions were used for the analysis. The result showed that composite contribution of personality traits, Self-concept, Achievement motivation and Academic Achievements ranged from $9.07 \%$ to $28.42 \%$ in the prediction of vocational interests. The study was concluded with implications and some important suggestions.
\end{abstract}

Keywords: Vocational interest, Self-Concept, Personality, Achievement, Motivation, Prediction.

\section{Introduction}

One of the basic \& important aims of education is to be self-sustained and self- reliant economically at the later stages of one's life on completion of the studies. Vocational interest is a single important factor which augurs strong about the chance of selection and inclination towards any profession/trade by an individual. Interest is the next most capable psychological factor after intelligence $\&$ ability to excel and reach on climax in any endeavor. Interest is an important construct for the depth of text comprehension, in learning strategies and quality emotional experiences in learning (Ulrich, 2011). To be in harmony with chosen field of work, there is an unavoidable requirement of synergy between one's occupation and interest in it. Any profession undertaken inadvertently would not only create a burdened life but also it could mar the performance and production significantly, as a 'Vocation' is not merely a source of wealth and prosperity but a fountain head of utter happiness. Lisa, et al. (2018) found that happiness and career success are deeply associated. Happiness improves positive emotions which lead to better out comes on job. Our golden and precious time of life is devoted to work. Therefore, the chosen work of an individual must be inconsonance with interest and ability possessed by him/her. An individual is recognized by his vocation upto his last breathe. Vocation provides recognition to an individual in the society, in addition to survival power in terms of basic needs. Apparently, one can notice that any one's vocation and his/her life activities including thought processes are inseparable from his/her vocation. Numerous studies have been noticed about vocational interest but as an independent variable. Vocational interest being important psychological factor in the world of work, it seems that there is an urgent requirement to explore as to what makes an individual to differ one from another in their interest of vocations despite being groomed and educated in the same schooling pattern. Vocational interests get crystallizing among the adolescents once they reach at terminal stages of their education i.e. from VIII to $\mathrm{X}$ standards of their Education. The present study was undertaken to analyze the vocational interest of $\mathrm{X}^{\text {th }}$ standard students and contributions of some the important psychological variables in developing it.

\section{Why this study is unique and important}

To perform and achieve any target in life, interest of an individual is found to be of paramount importance. It channelizes the energy and creates concentration to work incessantly. It has been noticed that vocational interests have mostly been studied as a predicator of occupational success, stability, performances etc but hardly could be seen any study which elaborates about the causes of developing a deep variation in the interest of various vocations. An effort has been made in the present study to measure the interest of vocations and its analysis in terms of important factors like personality traits, self-concept, achievement-motivation and academic achievements. How and up to what extent these factors can contribute in creation of an interest in any vocation. It might provide a unique insight about the shaping of vocational interests in association with these psychological factors and their contributions individually as well as collectively.

\section{Vocational Interest}

Interest is an intrinsic inclination to work in a particular field or direction more easily and enjoyably than other one. It creates and sustains attention long lasting. Bingham (1937) expressed "Interest is a tendency to become absorbed in an experience and to continue it."According to Strong (1943) an interest is not a separate psychological entity but merely one of several aspects of behaviors. "Interests are conditioned stimuli pursued because of their relations to 
goal objects which are valued. Interests in turn are extinguished as all other conditioned responses are extinguished when the relations to the drives involved are destroyed" (Murphy, 1947). Interest can be of four types (i) expressed interest - what a person expresses (ii) manifest interest - what a person actually does as an indication of what one's interests are, (iii) inventoried interest determined by the pattern of an individual's responses to lists of occupations or activities, and (iv) tested interest measurement of one's vocabulary in a particular area in the belief that if one is truly interested in that area (Super \& Crites, 1962). As per Crow and Crow (1964), interest can be interpreted as a motivating force that stimulates an individual to participate in one activity rather than in other. Holland (1973) defined vocational interests as "the expression of personality in work, hobbies, recreational activities, and preferences". "Interests are relatively stable psychological characteristics of people which identify the personal evaluation (subjective attributions of 'goodness' or 'badness,' judged degree of personal fit or misfit) attached to particular groups of occupational or leisure activity clusters" Lowman and Carson (2003).Vocation was initially conceptualized as a 'call' or 'summon' by almighty for an occupation and subsequently accepted as a developed talent and ability to perform in a selected career. "a type of work that you feel you are suited to doing and to which you should give all your time and energy, or the feeling that a type of work suits you in this way" Cambridge Academic Content Dictionary (2009). Berdie (1944) viewed vocational interests both as measured by tests and as indicated by occupational choices are the expressions of liking and disliking as directed toward activities, objects and characteristics of the environment. According to Dick and Rallis (1991) vocational interest are identified as individual differences that are vital to the career choice process. Further, vocational interest is understood as a crystallized pattern of likes, dislikes and indifferences regarding career relevant activities and occupations (Lent, et. al., 1994). Therefore, vocational interests of an individual are the likings in a vocation, which could be acquired and manifested due to environmental interactions, personality makeup or inherent.

\section{Literature Review}

Hoff, et al. (2018) studied the longitudinal changes in interest from adolescence to adulthood. Under metaanalysis, out of 49 longitudinal studies holding 98 total samples with 20,639 participants, it was found that gender differences associated with vocations touches peak during early adolescence and subsequently decreases. Overall, normative changes in vocational interests were observed. Singh (2018) investigated the interest of male and female in vocations on a sample of 80 (40 male and 40 female) students of $\mathrm{X}^{\text {th }}$ standard in $\mathrm{J} \& \mathrm{~K}$ districts. Vocational Interest Inventory (VII) developed by the investigator was used to collect the data. t-test was applied for the analysis. Significant differences in vocational interest was observed, girls found more interested in music, agriculture, and teaching than boys whereas boys showed inclination towards mechanical, outdoor, business, sports, social, executive and scientific areas. James (2017) studied occupations and interest in Australia. 1016 occupations were classified as per the vocational interest as outdoor, practical health, and community, computing etc, Educational qualifications, skills and Holland RIASEC types. Around half of the occupations found having practical interest. $80 \%$ of the occupations were having more than one interest contents whereas creative interest found least common of $9.2 \%$ occupations. Occupational interests were having relationship with skill grading and qualifications. The occupations which related to highest skills were scientific and computational whereas outdoor and practical jobs showed demanding lower skills. Yao-Ting, et al. (2016) analyzed career interest profiles of Junior High School Students. 13,853 students were sampled for the study of combined talent profile analysis and differentiation value of career interest. It was revealed that $44.6 \%$ of students were having low-differentiation profile (possessing like or dislike all types of vocational activities) out of 25 career interest profiles. $24.9 \%$ could be classified under Artistic-social profiles. Males and females differed significantly among the profiles, whereas grades did not have variation on profiles. Males showed higher proportion of low differentiation than females. Kurbanoglu and Arslan (2015) studied Educational and career interest and career adaptabilities of High school students, using educational and career interest scale and career adaptability scale. Data were collected on 702 ( 357 female, 345 male) students of high school standard. t-test, ANOVA, Pearson moment correlation and multiple regressions were taken to analyze the data. Significant difference between grade level of students and their educational and career interest scores were observed, a positive correlation was found between career interests and career adaptability. Zeshan et al. (2014) studied vocational interest of adolescents in relation to socio-economic status of XII standard students on a sample of 200 (100 Boys and 100 Girls) using vocational interest Record (VIR) by S.P. Kulshreshtha and Socio-Economic status scale (SESS) by Meenakshi. t-test and coefficient of correlation statistical tools were taken for the analysis. No significant difference found between vocational interests and socio-economic status among students. However, rural and urban students differed significantly in Executives, Commercial, Constructive, Artistic and Agriculture vocational interests. Mattoo (2013) studied career choices of secondary school students with special reference to gender, stream and parental education. On a sample of 200 students selected out of 12 secondary schools within age of 16 yrs, Non-language Preference Record by S. Chaterjee was administered. t-test and percentage analysis were devised to analyze the data. Parental education and gender were found significant factors in Career choices of the students. Otta and Williams (2012) studied self-concept and vocational interest of Adolescent on 799 students. The purposive random sampling was followed. To collect the data, Adolescent Personal Data Inventory (APDI) developed by 
Akinboye (1985) and Vocational Interest Inventory (VII) Bakare (1977) were used. Regression analysis, ANOVA, Ztest and correlation statistical techniques including Moreso frequency counts, percentages and ranks were applied to analyze the data. A significant relationship was found between self-concept and vocational interest. Scientific, literary, persuasive, computational and social services were liked most whereas less interest was shown in outdoor, mechanical, musical and artistic vocations by the students. Lyn, et al. (2011) studied the relationship between vocational interest, self-efficacy and Achievement in prediction of educational pathways. A total of 189 students between ages 14-15 years participated in the study. All the three constructs (Vocational interest, self-efficacy and Achievement) found significant in prediction of the pathway. Self-efficacy and achievement were best predictors for Artistic, social and conventional students for the future course of studies. Wille, et al. (2010) studied vocational interest and big five traits as predictors of job instability. On a long term cohort for 291 subjects, RIASEC interest profile and big personality scores were examined well before the professional career was undertaken. Individual differences was evident in the stability of jobs. Investigative, artistic, enterprising and conventional interests found important predictors whereas under big five personality traits, agreeableness and openness found having strongest association with job instability.

\section{Objective}

1. To study the vocational interests of terminal stage students (Class X).

2. To study the contribution of cognitive and noncognitive factors in the prediction of vocational interests.

\section{Hypothesis}

The following null hypotheses were designed;

H1: Personality traits, self-concept, achievement motivation and academic achievements are not the significant predictors of literary vocational interest.

$\mathrm{H} 2$ : Personality traits, self-concept, achievement motivation and academic achievements are not the significant predictors of scientific vocational interest.

H3: Personality traits, self-concept, achievement motivation and academic achievements are not the significant predictors of executive vocational interest.

H4: Personality traits, self-concept, achievement motivation and academic achievements are not the significant predictors of commercial vocational interest.

H5: Personality traits, self-concept, achievement motivation and academic achiever are not the significant predictors of constructive vocational interest.

H6: Personality traits, self-concept, achievement motivation and academic achievements are not the significant predictors of artistic vocational interest.

H7: Personality traits, self-concept, achievement motivation and academic achievements are not the significant predictors of agricultural vocational interest.
H8: Personality traits, self-concept, achievement motivation and academic achievements are not the significant predictors of persuasive vocational interest.

H9: Personality traits, self-concept, achievement motivation and academic achievements are not the significant predictors of social vocational interest.

H10: Personality traits, self-concept, achievement motivation and academic achiever are not the significant predictors of household vocational interest.

\section{Methodology}

The present study was designed to predict the vocational interest out of cognitive \& non-cognitive factors such as personality, self- concept, n-Achievement and academic achievements of the students. Multiple linear regressions were applied for the predication and Analysis.

\section{Sample}

8 CBSE affiliated schools managed under defense sectors located in the states of Karnataka, Tamil Nadu and A.P. having English as their medium of Instructions were randomly selected. Out of these schools, 272 (141 Boys and 131 Girls) students of $X^{\text {th }}$ standard formed the sample of the study.

\section{Tools Used}

To collect the date on vocational interest, personality traits, self-concepts and achievement motivation, following standardized tools were used.

Vocational Interest: To collect the data on vocational interest, Vocational Interest Record (VIR) developed by Kulshrestha (1977) was used. It has got test-retest reliability coefficient 0.69 and validity coefficient 0.81 to 0.85 .The VIR measures ten areas of vocational interest i.e Literary (L), Scientific (Sc), Executive (E), Commercial (C), Constructive (Co), Artistic (Ar), Agricultural (Ag), Persuasive (P), Social (S), Household (H).

Personality Traits: For the general assessment of Personality Traits, High School Personality Questionnaire (HSPQ), highly standardized test developed by Cattell and Cattell (1968) which measures fourteen factors of the personality. The tool is standardized with high degree of validity and reliability.

Self-Concept: To collect the data on self-concept, Children's Self-concept Scale (CSCS) developed by Ahluwalia (1986) was taken. It contains 80 items with six sub areas. It has got reliability coefficient from 0.79 to 0.83 and validity up to 0.62 which is significant even beyond 0.01 level of confidence.

Achievement Motivation: To assess achievement motivation, Deo-Mohan Achievement Motivation Scale (DMAMS) developed by Deo and Mohan (2002) was taken. The scale has got 50 items spread over fifteen factors. It is reliable with coefficient 0.69 to 0.78 and valid with coefficient 0.75 .

Academic Achievement: The overall scores obtained in the final exam by the students were taken for the analysis which 
includes five subjects, i.e. Hindi, English, Mathematics, Science and Social Studies.

\section{Justification of tools used for data collection}

Taking into account the need of the study, most appropriate reliable and valid tools were deliberated to select for each variable having suitability and practicability for the intended subject sample; as mentioned above vocational interest by Kulshrestha, Personality Traits by Cattell \& Cattell, Self-Concepts by Ahluwalia and Achievement Motivation by Deo and Mohan were finalized and used as the same was concurred in by the experts.

Variables: Personality Traits, Self-concept, Achievement Motivation and Academic Achievements were taken as independent variables and Vocation interest (including all the ten areas) was taken as dependent variable in the present study.
Data Collection: Data were collected using afore said standardized four tools, in addition to, their final academic scores. In order to get fair information, the tools were administered in different seatings and dates. The subjects were explained about methodology of their answering techniques and doubts if any were clarified before commencement of the test.

\section{Analysis and Result}

Multiple regression analysis was used to analyze the data. Results are presented as per the hypothesis as given below.

H1: Personality traits, self-concept, achievement motivation and academic achievements are not the significant predictors of literary vocational interest.

Table 1: Multiple linear regressions for literary vocational interest

\begin{tabular}{|l|c|c|c|c|c|}
\hline \multicolumn{1}{|c|}{ Independent Variables } & Beta & SE of Beta & Reg. Coeffi. & SE of Coeffi. & t-value \\
\hline Intercept & & & 13.3425 & 3.6144 & $3.6915^{*}$ \\
\hline Personality traits $\left(\mathrm{X}_{\mathrm{I}}\right)$ & 0.3218 & 0.0625 & 0.1205 & 0.0234 & $5.1488^{*}$ \\
\hline Self- concept $\left(\mathrm{X}_{2}\right)$ & 0.3188 & 0.0644 & 0.1436 & 0.0290 & $4.9503^{*}$ \\
\hline Achievement Motivation $\left(\mathrm{X}_{3}\right)$ & 0.3159 & 0.0664 & 0.0671 & 0.0141 & $4.7575^{*}$ \\
\hline Academic Achievement $\left(\mathrm{X}_{4}\right)$ & 0.1361 & 0.0830 & 0.0347 & 0.0212 & 1.6398 \\
\hline $\mathrm{R}=0.3770, \mathrm{R}^{2}=0.1421, \mathrm{~F}=7.8185$ Sign at $\mathrm{P}<0.05$, Std, Error of estimates : $15.3241, * 0.05$ level \\
\hline
\end{tabular}

The multiple linear regression equation to predict the literacy vocational interest $\left(\mathrm{Y}_{1}\right)$ is calculated as, $\mathrm{Y} 1=$ $13.3425+0.1205 \mathrm{X}_{1}+0.1436 \mathrm{X}_{2}+0.671 \mathrm{X}_{3}+0.0347 \mathrm{X}_{4}$ The F-ratio 7.8185 for multiple correlation coefficients $\mathrm{R}=$ 0.3770 is found significant. It means estimation of literary vocational interest by the variables Personality traits, Selfconcept, Achievement motivation, and academic achievements is possible. Therefore, the null hypothesis is rejected. Further the $\mathrm{t}$-values of the partial regression coefficient of the variables $X_{1}, X_{2}$ and $X_{3}$ found significant at 0.05 level of confidence.

H2: Personality Traits, Self-concept, Achievement motivation and academic achievements are not the significant predictors of scientific vocational interest.

Table 2: Multiple linear regressions for scientific vocational interest

\begin{tabular}{|l|c|c|c|c|c|}
\hline Independent Variables & Beta & SE of Beta & Reg. Coeffi. & SE of Coeffi. & t-value \\
\hline Intercept & & & 10.5302 & 3.7131 & 2.8360 \\
\hline Personality traits $\left(\mathrm{X}_{\mathrm{I}}\right)$ & 0.5527 & 0.1061 & 0.1256 & 0.0241 & $5.2107^{*}$ \\
\hline Self- concept $\left(\mathrm{X}_{2}\right)$ & 0.3772 & 0.0626 & 0.1796 & 0.0298 & $6.0256^{*}$ \\
\hline Achievement Motivation $\left(\mathrm{X}_{3}\right)$ & 0.4269 & 0.0645 & 0.0959 & 0.0145 & $6.6186^{*}$ \\
\hline Academic Achievement $\left(\mathrm{X}_{4}\right)$ & 0.0885 & 0.0502 & 0.0235 & 0.0133 & 1.7629 \\
\hline \multicolumn{2}{|l|}{$\mathrm{R}=0.4899, \mathrm{R}^{2}=0.2400, \mathrm{~F}=14.90225$} \\
\hline
\end{tabular}

The Multiple Linear Regression Equation to predict the Scientific interest $\left(\mathrm{Y}_{2}\right)$ is calculated as, $\mathrm{Y}_{2}=10.5302+$ $0.1256 \mathrm{X}_{1}+0.1796 \mathrm{X} 2+0.0959 \mathrm{X} 3+0.0235 \mathrm{X}_{4}$.

The F-ratio 14.90225 for the multiple correlation coefficients $R=0.4899$ is found significant. It means prediction of scientific vocational interest by the variables personality traits, self-concept, achievement motivation, and academic achievements is possible. Therefore, the null hypothesis is rejected. Further the t-values of the partial Regression coefficient of the variables $X_{1}, X_{2}$ and $X_{3}$ found significant at 0.05 level of confidence.

H3: Personality Traits, self-concept, achievement motivation and academic achievements are not the significant predictors of executive vocational interest. 
Table 3: Multiple linear regressions for executive vocational interest

\begin{tabular}{|l|c|c|c|c|c|}
\hline \multicolumn{1}{|c|}{ Independent Variables } & Beta & SE of Beta & Reg. Coeffi. & SE of Coeffi. & t-value \\
\hline Intercept & & & 6.6661 & 1.3621 & $4.8940^{*}$ \\
\hline Personality traits $\left(\mathrm{X}_{\mathrm{I}}\right)$ & 0.1535 & 0.0918 & 0.0473 & 0.0283 & 1.6721 \\
\hline Self- concept $\left(\mathrm{X}_{2}\right)$ & 0.4199 & 0.0637 & 0.2281 & 0.0346 & $6.5918^{*}$ \\
\hline Achievement Motivation $\left(\mathrm{X}_{3}\right)$ & 0.1053 & 0.0656 & -0.0273 & 0.0170 & -1.6052 \\
\hline Academic Achievement $\left(\mathrm{X}_{4}\right)$ & 0.2909 & 0.0623 & 0.0182 & 0.0039 & $4.6693^{*}$ \\
\hline \multicolumn{2}{|l|}{$\mathrm{R}=0.3794, \mathrm{R}^{2}=0.1440, \mathbf{F}=\mathbf{7 . 9 3 8 1}$ ign at $\mathrm{P}<0.05$, Std, Error of estimates : $11.6541, * 0.05$ level } \\
\hline
\end{tabular}

The multiple linear regression equation to predict the Executive vocational interest $\left(\mathrm{Y}_{3}\right)$ is calculated as, $\mathrm{Y}_{3}=$ $6.6661+0.0473 X_{1}+0.2281 X_{2}-0.0273 X_{3}+0.0182 X_{4}$ The F-ratio 7.9381 for the multiple correlation coefficients $\mathrm{R}=0.3794$ is found significant. Therefore, the null hypothesis is rejected. Further the t-values of the partial regression coefficient of the variables $\mathrm{X}_{2}$ and $\mathrm{X}_{4}$ found significant at 0.05 level of confidence.

H4: Personality traits, self-concept, achievement motivation and academic achievements are not the significant predictors of commercial vocational interest.

Table 4: Multiple linear regressions for commercial vocational interest

\begin{tabular}{|l|c|c|c|c|c|}
\hline \multicolumn{1}{|c|}{ Independent Variables } & Beta & SE of Beta & Reg. Coeffi. & SE of Coeffi. & t-value \\
\hline Intercept & & & 6.3258 & 1.2563 & $5.0353^{*}$ \\
\hline Personality traits $\left(\mathrm{X}_{\mathrm{I}}\right)$ & 0.1938 & 0.0619 & 0.0810 & 0.0211 & $3.1302^{*}$ \\
\hline Self- concept $\left(\mathrm{X}_{2}\right)$ & 0.1084 & 0.0638 & 0.0035 & 0.0261 & 1.6991 \\
\hline Achievement Motivation $\left(\mathrm{X}_{3}\right)$ & -0.1221 & 0.0658 & -0.0236 & 0.0127 & -1.8556 \\
\hline Academic Achievement $\left(\mathrm{X}_{4}\right)$ & 0.2078 & 0.0624 & 0.0097 & 0.0029 & $3.3301^{*}$ \\
\hline $\mathrm{R}=0.3012, \mathrm{R}^{2}=0.0907, \mathrm{~F}=4.7101$ Sign at $\mathrm{P}<0.05$, Std, Error of estimates : 17.3001, *0.05 level \\
\hline
\end{tabular}

The multiple linear regression equation to predict the commercial interest $(\mathrm{Y} 4)$ is calculated as, $\mathrm{Y}_{4}=6.3258+$ $0.0810 \mathrm{X}_{1}+0.0035 \mathrm{X}_{2}-0.0236 \mathrm{X}_{3}+0.0097 \mathrm{X}_{4}$. The F-ratio 4.7101 for the multiple correlation coefficients $\mathrm{R}=0.3012$ is found significant. It means that estimation of commercial vocational interest by the variables Personality traits, Selfconcept, achievement motivation, and academic achievements is possible. Therefore, the null hypothesis is rejected. Further the $\mathrm{t}$-values of the partial regression coefficient of the variables $\mathrm{X}_{1}$ and $\mathrm{X}_{4}$ found significant at 0.05 level of confidence.

H5: Personality traits, self-concept, achievement motivation and academic achiever are not the significant predictors of constructive vocational interest.

Table 5: Multiple linear regressions for constructive vocational interest

\begin{tabular}{|l|c|c|c|c|c|}
\hline \multicolumn{1}{|c|}{ Independent Variables } & Beta & SE of Beta & Reg. Coeffi. & SE of Coeffi. & t-value \\
\hline Intercept & & & 11.8292 & 3.2547 & $3.6345^{*}$ \\
\hline Personality traits $\left(\mathrm{X}_{\mathrm{I}}\right)$ & 0.3705 & 0.0660 & 0.1681 & 0.0300 & $5.6128^{*}$ \\
\hline Self- concept $\left(\mathrm{X}_{2}\right)$ & 0.3052 & 0.0482 & 0.1520 & 0.0240 & $6.3326^{*}$ \\
\hline Achievement Motivation $\left(\mathrm{X}_{3}\right)$ & 0.2890 & 0.0574 & 0.0473 & 0.0094 & $5.0354^{*}$ \\
\hline Academic Achievement $\left(\mathrm{X}_{4}\right)$ & 0.3983 & 0.0871 & 0.0554 & 0.0121 & $4.5747^{*}$ \\
\hline $\mathrm{R}=0.5331, \mathrm{R}^{2}=0.2842, \mathrm{~F}=18.7404$ Sign at $\mathrm{P}<0.05$, Std, Error of estimates : $13.0165, * 0.05$ level \\
\hline
\end{tabular}

The multiple linear regression equation to predict the constructive interest $\left(\mathrm{Y}_{5}\right)$ is calculated as, $\mathrm{Y}_{5}=11.8292+$ $0.1681 \mathrm{X}_{1}+0.1520 \mathrm{X}_{2}+0.0473 \mathrm{X}_{3}+0.0554 \mathrm{X}_{4}$. The F-ratio 18.7404 for $\mathrm{R}=0.5331$ is found significant. Therefore, the null hypothesis is rejected. Further the t-values of the partial regression coefficient for $X_{1}, X_{2}, X_{3}$ and $X_{4}$ found significant.

H6: Personality Traits, Self-concept, Achievement motivation and Academic Achievements are not the significant predictors of Artistic vocational interest.

Table 6: Multiple linear regressions for artistic vocational interest

\begin{tabular}{|l|c|c|c|c|c|}
\hline & Beta & SE of Beta & Reg. Coeffi. & SE of Coeffi. & t-value \\
\hline Intercept & & & 5.2147 & 1.0214 & $5.1054 *$ \\
\hline Personality traits $\left(\mathrm{X}_{\mathrm{I}}\right)$ & 0.4317 & 0.0546 & 0.2158 & 0.0273 & $7.9062^{*}$ \\
\hline Self- concept $\left(\mathrm{X}_{2}\right)$ & 0.2032 & 0.1100 & 0.0788 & 0.0427 & 1.8473 \\
\hline Achievement Motivation $\left(\mathrm{X}_{3}\right)$ & -0.117 & 0.0589 & -0.0526 & 0.0264 & -1.9913 \\
\hline Academic Achievement $\left(\mathrm{X}_{4}\right)$ & 0.3254 & 0.0451 & 0.0647 & 0.0090 & $7.2119^{*}$ \\
\hline $\mathrm{R}=0.4051, \mathrm{R}^{2}=0.1641, \mathrm{~F}=9.2690$ Sign at $\mathrm{P}<0.05$, Std, Error of estimates : $16.2014, * 0.05$ level \\
\hline
\end{tabular}


The multiple linear regression equation to predict the artistic interest $\left(\mathrm{Y}_{6}\right)$ is calculated as, $\mathrm{Y}_{6}=5.2147+0.2158$ $\mathrm{X}_{1}+0.0788 \mathrm{X}_{2}-0.0526 \mathrm{X}_{3}+0.0647 \mathrm{X}_{4}$. The F-ratio 9.2690 for $\mathrm{R}=0.4051$ is found significant. Therefore, the null hypothesis is rejected. Further the t-values of the partial Regression coefficient for $\mathrm{X}_{1}$ and $\mathrm{X}_{4}$ found significant.

H7: Personality traits, self-concept, achievement motivation and academic achievements are not the significant predictors of agricultural vocational interest.

Table 7: Multiple linear regressions for agricultural vocational interest

\begin{tabular}{|l|c|c|c|c|c|}
\hline \multicolumn{1}{|c|}{ Independent Variables } & Beta & SE of Beta & Reg. Coeffi. & SE of Coeffi. & t-value \\
\hline Intercept & & & 9.5692 & 1.6225 & $5.8978^{*}$ \\
\hline Personality traits $\left(\mathrm{X}_{\mathrm{I}}\right)$ & -0.0674 & 0.0622 & -0.0255 & 0.0235 & -1.0836 \\
\hline Self- concept $\left(\mathrm{X}_{2}\right)$ & -0.3744 & 0.0641 & -0.1698 & 0.0291 & $-5.8406^{*}$ \\
\hline Achievement Motivation $\left(\mathrm{X}_{3}\right)$ & -0.4098 & 0.0550 & -0.1052 & 0.0141 & $-7.4509^{*}$ \\
\hline Academic Achievement $\left(\mathrm{X}_{4}\right)$ & -0.3584 & 0.0626 & -0.0184 & 0.0032 & $-5.7252^{*}$ \\
\hline \multicolumn{2}{|l}{$\mathrm{R}=0.4376, \mathrm{R}^{2}=0.1915, \mathrm{~F}=11.1779$ at $\mathrm{P}<0.05$, Std, Error of estimates : $14.2987,{ }^{*} 0.05$ level } \\
\hline
\end{tabular}

The multiple linear regression equation to predict the agricultural interest $\left(\mathrm{Y}_{7}\right)$ is calculated as, $\mathrm{Y}_{7}=9.5692-$ $0.0255 \mathrm{X}_{1}-0.1698 \mathrm{X}_{2}-0.1052 \mathrm{X}_{3}-0.0184 \mathrm{X}_{4}$. The F-ratio 11.1779 for $R=0.4376$ is found significant. Therefore, the null hypothesis is rejected. Further, the t-values of the partial regression coefficient for $\mathrm{X}_{2}, \mathrm{X}_{3}$ and $\mathrm{X}_{4}$ also found significant.

H8: Personality traits, self-concept, achievement motivation and academic achievements are not the significant predictors of persuasive vocational interest.

Table 8: Multiple linear regressions for persuasive vocational interest

\begin{tabular}{|l|c|c|c|c|c|}
\hline \multicolumn{1}{|c|}{ Independent Variables } & Beta & SE of Beta & Reg. Coeffi. & SE of coeffi. & t-value \\
\hline Intercept & & & 5.2689 & 2.0514 & 2.5684 \\
\hline Personality traits $\left(\mathrm{X}_{\mathrm{I}}\right)$ & 0.3814 & 0.0621 & 0.1470 & 0.0239 & $6.1417^{*}$ \\
\hline Self- concept $\left(\mathrm{X}_{2}\right)$ & 0.1616 & 0.0940 & 0.1908 & 0.1110 & 1.7191 \\
\hline Achievement Motivation $\left(\mathrm{X}_{3}\right)$ & 0.3421 & 0.0660 & 0.1783 & 0.0344 & $5.1834^{*}$ \\
\hline Academic Achievement $\left(\mathrm{X}_{4}\right)$ & 0.4109 & 0.0626 & 0.0217 & 0.0033 & $6.5639^{*}$ \\
\hline \multicolumn{2}{|l}{$\mathrm{R}=0.4252, \mathrm{R}^{2}=0.1808, \mathrm{~F}=10.4178$ Sign at $\mathrm{P}<0.05$, Std, Error of estimates : $16.9514, * 0.05$ level } \\
\hline
\end{tabular}

The multiple linear regression equation to predict the persuasive interest $\left(\mathrm{Y}_{8}\right)$ is calculated as, $\mathrm{Y}_{8}=5.2689+$ $0.1470 \mathrm{X}_{1}+0.1908 \mathrm{X}_{2}+0.1783 \mathrm{X}_{3}+0.0217 \mathrm{X}_{4}$. The F-ratio 10.4178 for $\mathrm{R}=0.4252$ is found significant. Therefore, the null hypothesis is rejected. Further, the t-values of the partial regression coefficient for $X_{1}, X_{3}$ and $X_{4}$ found significant.

H9: Personality traits, self-concept, achievement motivation and academic achievements are not the significant predictors of social vocational interest.

Table 9: Multiple linear regressions for social vocational interest

\begin{tabular}{|l|c|c|c|c|c|}
\hline \multicolumn{1}{|c|}{ Independent Variables } & Beta & SE of Beta & Reg. Coeffi. & SE of Coeffi. & t-value \\
\hline Intercept & & & 5.3247 & 1.6587 & $3.2102^{*}$ \\
\hline Personality traits $\left(\mathrm{X}_{\mathrm{I}}\right)$ & 0.3014 & 0.0621 & 0.1160 & 0.0239 & $4.8535^{*}$ \\
\hline Self- concept $\left(\mathrm{X}_{2}\right)$ & 0.1616 & 0.1164 & 0.0789 & 0.0568 & 1.3883 \\
\hline Achievement Motivation $\left(\mathrm{X}_{3}\right)$ & 0.4489 & 0.0660 & 0.2340 & 0.0344 & $6.8015^{*}$ \\
\hline Academic Achievement $\left(\mathrm{X}_{4}\right)$ & 0.1910 & 0.1063 & 0.0185 & 0.0103 & 1.7975 \\
\hline $\mathrm{R}=0.3254, \mathrm{R}^{2}=0.1371, \mathrm{~F}=8.4478$ Sign at $\mathrm{P}<0.05$, Std, Error of estimates : $15.9514, * 0.05$ level \\
\hline
\end{tabular}

The multiple linear regression equation to predict the Social interest $\left(\mathrm{Y}_{9}\right)$ is calculated as, $\mathrm{Y} 9=5.3247+0.1160$ $\mathrm{X}_{1}+0.0789 \mathrm{X}_{2}+0.2340 \mathrm{X}_{3}+0.0185 \mathrm{X}_{4}$. The F-ratio 8.4478 for $\mathrm{R}=0.3254$ is found significant. Therefore, the null hypothesis is rejected. Further, the t-values of the partial Regression coefficient for $\mathrm{X}_{1}$ and $\mathrm{X}_{3}$ found significant.

H10: Personality traits, self-concept, achievement motivation and academic achiever are not the significant predictors of household vocational interest.

Table 10: Multiple linear regressions for household vocational interest

\begin{tabular}{|l|c|c|c|c|c|}
\hline Independent Variables & Beta & SE of Beta & Reg. Coeffi. & SE of Coeffi. & t-value \\
\hline Intercept & & & 3.5821 & 1.0931 & $3.2770^{*}$ \\
\hline Personality traits $\left(\mathrm{X}_{\mathrm{I}}\right)$ & -0.3989 & 0.0574 & -0.1077 & 0.0237 & $-6.9488^{*}$ \\
\hline Self- concept $\left(\mathrm{X}_{2}\right)$ & -0.1009 & 0.0592 & -0.0501 & 0.0294 & -1.7044 \\
\hline Achievement Motivation $\left(\mathrm{X}_{3}\right)$ & -0.4029 & 0.0570 & -0.2417 & 0.0342 & $-7.0684^{*}$ \\
\hline Academic Achievement $\left(\mathrm{X}_{4}\right)$ & 0.4093 & 0.0888 & 0.0152 & 0.0033 & $4.6103^{*}$ \\
\hline $\mathrm{R}=0.4178, \mathrm{R}^{2}=0.1746, \mathrm{~F}=9.9831$, Sign at $\mathrm{P}<0.05$, Std, Error of estimates : 15.9856, *0.05 level \\
\hline
\end{tabular}


Table 11: Summary of percentage contributions in predicting vocational interests (V.Is.)

\begin{tabular}{|c|c|c|c|c|c|c|c|c|c|c|c|}
\hline $\begin{array}{l}\dot{z} \\
\dot{s}\end{array}$ & 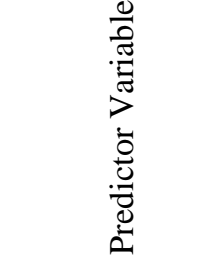 & 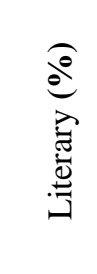 & 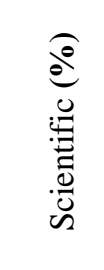 & 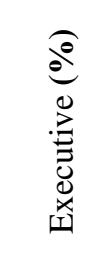 & 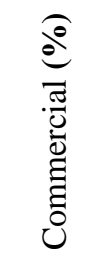 & 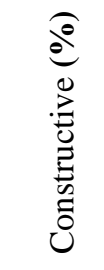 & 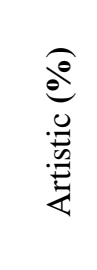 & 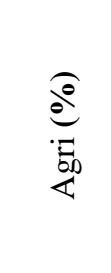 & 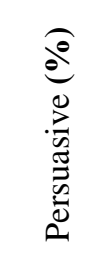 & 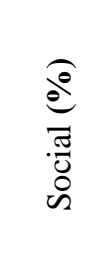 & $\begin{array}{l}\widehat{o} \\
0 \\
0 \\
0 \\
0 \\
0 \\
0 \\
0 \\
\text { I. }\end{array}$ \\
\hline 1. & Personality & 4.35 & 8.29 & 1.82 & 2.29 & 5.94 & 7.04 & 1.24 & 5.73 & 4.36 & 6.07 \\
\hline 2. & Self Concept & 5.18 & 5.62 & 7.43 & 1.14 & 5.26 & 2.28 & 5.75 & 2.07 & 0.40 & 1.07 \\
\hline 3. & $\begin{array}{l}\text { Achievement - } \\
\text { Motivation }\end{array}$ & 3.63 & 9.42 & 0.02 & 1.47 & 5.35 & 0.63 & 6.34 & 3.3 & 7.48 & 7.25 \\
\hline 4. & $\begin{array}{c}\text { Academic - } \\
\text { Achievement }\end{array}$ & 1.05 & 0.67 & 5.13 & 4.17 & 11.87 & 6.46 & 5.82 & 6.98 & 1.47 & 3.07 \\
\hline & Total & 14.21 & 24.00 & 14.40 & 9.07 & 28.42 & 16.41 & 19.15 & 18.08 & 13.71 & 17.46 \\
\hline
\end{tabular}

The multiple linear regression equation to predict the household interest $\left(\mathrm{Y}_{10}\right)$ is calculated as, $\mathrm{Y}_{10}=3.5821$ $0.1077 \mathrm{X} 1-0.0501 \mathrm{X}_{2}-0.2417 \mathrm{X}_{3}+0.0152 \mathrm{X}_{4}$. The F-ratio 9.9831 for $\mathrm{R}=0.4178$ is found significant. Therefore, the null hypothesis is rejected. Further, the t-values of the partial Regression coefficient of the variables $\mathrm{X}_{1}$ and $\mathrm{X}_{3}$ found significant at 0.05 level of confidence. The prediction of individual vocational interest by the independent variables was estimated and the summary is placed on the table above (Table 11).

\section{Discussion}

The personality traits, self-concept, $n$-achievement and academic achievements were found significant predictors of vocational interests. Personality traits found highest contributor to predict the vocation of scientific interest which is $8.29 \%$ and poor contributor to guess in developing Agricultural vocational interest i.e. 1.24\%. Self-concept turned out to be highest predictor for vocation in Executive area which is $7.43 \%$ but remained decimal for Social interest field. Achievement motivation showed empirically it can contribute $9.42 \%$ to predict vocation of scientific interest and least for executive interest $0.02 \%$ which is negligible, the fourth predictor academic achievement found highest contributor for constructive vocational interest i.e. $11.87 \%$ and lowest $0.67 \%$ for scientific interest. It is divulged that out of the ten areas of vocational interests, constructive and scientific areas found highest among all, which could be predicted jointly by the personality traits, self-concept, achievement motivation and academic achievement $28.42 \%$ and $24 \%$ respectively. However, these variables together found having predicting ability lowest i.e. $9.07 \%$ for the vocations of commercial interest. Further among all the four variables, the highest contributor in prediction of vocational interest is found academic Achievement for the constructive vocations which is $11.87 \%$. Some contrary result was also noticed, as against conventional belief that good academic scores could create more interest in scientific vocations, this connotation was denied as academic achievement found poor predictor of scientific vocations which was as low as $0.67 \%$, whereas personality traits seen highest contributor to guess about interest of scientific vocations.

\section{Conclusion}

1. Vocational interests can be predicted significantly by the cognitive and non-cognitive factors of an individual.

2. Personality traits could predict the vocation of scientific, artistic and constructive, interests effectively.

3. Self concept can contribute to guess about vocations of executive interest more than any other vocational interests.

4. Achievement motivation can predict the vocations of scientific interest close to $10 \%$.

5. Academic achievement is significant predictor variable for the vocation of Constructive interest.

\section{Implications and Suggestions}

1. According to the result, it is found that the predictor variables, personality traits, Self-concept, Achievement motivation and Academic Achievements together could only contribute from $9.07 \%$ to $28.42 \%$ in assessing the prediction e.g. $24 \%$ in the prediction of scientific interest, remaining percentage are unknown as to what are the factors responsible for assessing the vocational interests. Further studies could be undertaken on the subject to explore possibilities.

2. Counseling centers if not feasible in every school then at least for the cluster of schools may be provisioned to provide career and vocational counseling for the students of terminal stages like $\mathrm{X}^{\text {th }} \& \mathrm{XII}^{\text {th }}$ standards.

3. Cognitive and non-Cognitive factors of the learners need to be assessed at a regular intervals and a psychological Record card (PRC) can be maintained accordingly, it would not only assist in their Vocational Assessment but also help in quick decision making for the parents and pedagogues as well.

4. Vocational Information plays an important role to make choices and enter in the world of work. Data based 
authenticated information pertaining to vocations is also need of the hour for the adolescents which could be easily apprised or referred readily.

5. Career counsellors need to present positivity and optimism in every vocation as per the interests and ability to an individual, as the pseudo- prestige and pride for a vocation which has got a mismatch with the interest of an individual can jeopardize the inner strength and zeal to excel in opted field.

\section{References}

1. Ahluwalia S.P. (1986). Children Self Concept Scale (CSCS). Agra: National Psychological Corporation.

2. Akinboye J. O. (1985). Adolescent Personal Data Inventory (APDI): Users' Manual. Ibadan: Claveeranium Press.

3. Bakare G. G.M. (1977). Vocational Interest Inventory, Psychological Research Production, University of Ibadan.

4. Berdie R.F. Factors associated with Vocational Interest. Psychological Bulletin, 1944;41(3):137-157.

5. Bingham W.V. (1937).Aptitudes and Aptitude Testing. Newyork; Harper and Brothers Publishers.

6. Cambridge Academic Content Dictionary (2009). Definition of 'vocation'. New York: Cambridge University Press.

7. Cattell, R.B. and Cattell, M.D. (1968). Manual for the $\mathrm{jr}-\mathrm{Sr}$ High School Personality Questionnaire 'HSPQ'. Champaign, IL: Institute of Personality and ability Testing.

8. Crow L.D, and Crow A. (1964). Adolescent development and adjustment. Newyork; Mc Graw Hill Publishing, p-173.

9. Deo, P. and Mohan, A. (2002). Deo-Mohan Achievement Motivation. Agra: National Psychological Corporation.

10. Dick T.P. and Rallis, S.F. Factors and influences on high school students career choices. Journal of Research in Mathematics Education, 1991;22(4):281-292.

11. Hoff, K. A., Briley, D. A., Wee, Colin J. M., James R. Normative changes in interests from adolescence to adulthood: A meta-analysis of longitudinal studies. Psychological Bulletin, 2018;144(4):426-451.

12. Holland, J. L. (1973). Making vocational choices: A theory of careers. Upper Saddle River, NJ: Prentice Hall. P- 7.

13. James, A. A. (2017). A preliminary examination of occupations and interests in Australia. Australian Journal of Career Development, 26(2), 81-88. doi :10.1177 $/ 1038416217718364$.

14. Kulshrestha, S.P. (1977). Vocational Interest Record (VIR). Agra; National Psychological Corporation.

15. Kurbanoglu, N.I. and Arslan, S. (2015). The educational and career interest scale in science, technology, and mathematics: Validity and reliability study. International journal of Human Sciences, 12(1), 1477-1484. doi: 10.14687/ijhs.v12i1.3158.

16. Lent, R.W., Brown S.D. and Hackett, G. (1994). Toward a unifying social cognitive theory of career and academic interest, choice and performance. Journal of Vocational Behaviour, 45(1), 79-122.

17. Lisa, C. Walsh, Julia K. B. and Lyubomirsky, S. (2018). Does Happiness Promote Career Success? Revisiting the Evidence. Journal of Career Assessment, 2018;26(2):199-219. DOI: $10.1177 / 1069072717751441$.

18. Lowman, R.L. and Carson A.D. (2003). Assessment of Interests. https://onlinelibrary. wiley.com/doi/10.1002/0471264385.wei1020.P-478.

19. Lyn, P., Esther, C. and Mary, A. The Relationship between Vocational Interests, Self-Efficacy, and Achievement in the Prediction of Educational Pathways. Journal of Career Assessment, 2011;19(1):61-74. DOI: $10.1177 / 1069072710382615$.

20. Mattoo, M.I. Career Choices of Secondary Students with Special Reference to Gender, Type of Stream and Parental Education. Research on Humanities and Social Sciences, 2013;3(20):55-61.

21. Murphy G. (1947).Personality-a biological approach to origins and structure. Newyork; Harpor and brothers. pp 7-8.

22. Otta F.E., and Williams, N.O. (2012). Self - concept and Vocational Interest among secondary school students (adolescents). Asian journal of social sciences \& humanities, 1(4), 37-48. www.ajssh.leena-luna.co.jp.

23. Singh, M. Assessment of Vocational Interests of Pahadi \& Bakarwal school students In relation to their gender. International Journal of Recent Scientific Research, 2018;9(3C):24817-24819. DOI: 10.24327/IJRSR.

24. Strong, E. K., Jr. (1943). Vocational interests of men and women. Stanford, CA: Stanford University Press.

25. Super D. E., \& Crites, J. O. (1962). Appraising vocational fitness (2nd ed.). New York: Harper \&Bros.

26. Ulrich, S. Interest, Learning and Motivation. Educational Psychologist, 2011;26(3-4):299323. DOI: $10.1080 / 00461520.1991 .9653136$.

27. Wille B, Filip De F and Feys M. Vocational interests and Big Five traits as predictors of job instability. Journal of Vocational Behavior, 2010;76(3):547-558.

28. Yao-Ting S., Yu-Wen, C. \& Jen-Hu, H. (2016). Identifying the Career-Interest Profiles of Junior-High-School Students through Latent Profile Analysis. The Journal of Psychology, 151:3, 229-246.

DOI: $10.1080 / 00223980.2016 .1261076$.

29. Zeshan H. Chandwani, S. and Rani, S. Vocational Interest of Adolescents in relation to the socio-economic status. ACADEMICIA: An International multidisciplinary Research Journal, 2014;4(1):21-36.

How to cite this article: Tewari V.P and Shailaja H.M. Predictors of vocational interest. J Manag Res Anal. 2018;5(4):447-454 